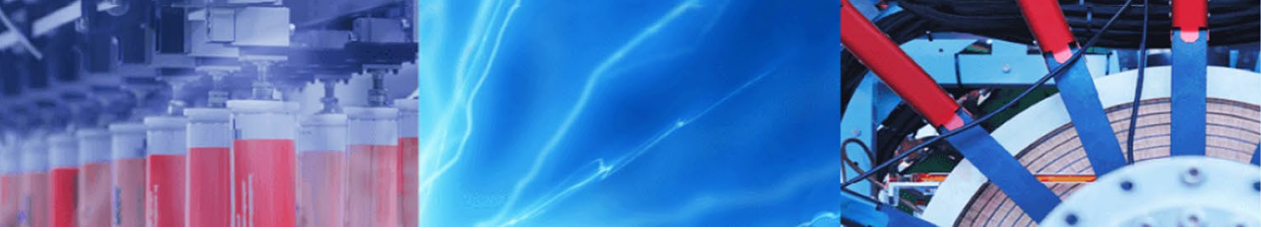

Research Article

\title{
Isotherm and thermodynamic studies of 2,4,6 Tichlorophenol onto newly adsorbents based zeolite as an efficient adsorbents
}

\author{
Atyaf Khalid Hameed ${ }^{1} \cdot$ Mohd Hasbi Ab. Rahim ${ }^{2} \cdot$ Nugroho Dewayanto $^{3} \cdot$ Mohd Ridzuan Nordin $^{4}$
}

C) Springer Nature Switzerland AG 2019

\begin{abstract}
The aim of this study is to evaluate the adsorption efficiency of using zero valent iron supported on carbon-coated zeolite NZVI/SuZSM and zeolite NZVI/ZSM and as developed adsorbents for the removal of 2,4,6- Trichlorophenol (TCP) from aqueous solution. The characteristic of the adsorbents was conducted via XRD, BET (SBET), TGA, FTIR, FESEM-EDX, and TEM examination. In addition, the impact of different parameters such as contact time, initial concentration, $\mathrm{pH}$ and temperature were studied. The experimental data investigated by Langmuir and Freundlich adsorption isotherms and two models for kinetic studies of pseudo-first-order and pseudo-second-order models. The results indicated that the adsorption studies fitted well with Langmuir for the adsorbent NZVI/SuZSM and fitted well with Freundlich for the adsorbent NZVI/ZSM. In addition, both models fitted the data well but pseudo-second-order models more favorable with correlation values of R2 of 0.9995 and 0.9994 more than first order models for the adsorbents NZVI/ZSM and NZVI/ SuZSM, respectively. The equilibrium time was achieved after $90 \mathrm{~min}$ for both adsorbents. Depending on the Langmuir model, the maximum adsorption capacities were $22.27 \mathrm{mg} / \mathrm{g}$ and $30.58 \mathrm{mg} / \mathrm{g}$ for NZVI/ZSM and NZVI/SuZSM, respectively at $\left(27^{\circ} \mathrm{C} \pm 2\right)$. The thermodynamic parameters indicated that adsorption of TCP onto NZVI/ZSM was an endothermic and non-spontaneous process in temperature of $30^{\circ} \mathrm{C}$, while the adsorption of TCP onto NZVI/SuZSM was an endothermic and spontaneous process. The synthesize adsorbents (NZVI/ZSM and NZVI/SuZSM) could be applied as an efficient adsorbent for the removal of TCP from aqueous solution.
\end{abstract}

Keywords Supported nano zero valent iron · 2,4,6-Trichlorophenpl adsorption · Carbon coated materials · Adsorption . Kinetic studies · Thermodynamic aspect

\section{Introduction}

The development of the chemical industry has produced increasing the disposal of pollutants, especially organic pollutant. Wastewater contains chlorophenol pollutants generated from pharmaceuticals, paper, wood, pesticide, solvent, paint, industries, and water disinfecting process [4]. These persistent organic pollutants (POPs) have existed in water and soil because they have three chloride groups linked to the phenol ring. The 2,4,6-Trichlorophenol (TCP) is one of POPs compound and it is harmful to wildlife and human as well as listed as precedence-controlled pollutant by the United States Environmental Protection Agency (USEPA). The TCP compound was toxic, carcinogenic and mutagenic. Also reiterate and long exposures can cause kidney, Liver, bone and neurological marrow disorders and also the loss of anemia, appetite, and weight loss. Thus, TCP presence in water resources even at low concentrations is injurious to aquatic organisms and human health. According to the chemical characteristics and

$\triangle$ Atyaf Khalid Hameed, atyaf.ump2015@gmail.com | ${ }^{2}$ Environmental and Water Research Technology Directorate, Ministry of Sciences and Technology, Al-Jadirya, Baghdad, Iraq. ${ }^{2}$ Faculty of Industrial Sciences and Technology, University Malaysia Pahang, Lebuhraya Tun Razak, 26300 Kuantan, Pahang, Malaysia. ${ }^{3}$ University Kuala Lumpur, Malaysian Institute of Chemical and Bioengineering Technology, Vendor City 1988, 78000 Alor Gajah, Melaka, Malaysia. ${ }^{4}$ Faculty of Technology Management and Technopreneurship, University Technical Malaysia Melaka, Hang Tuah Jaya, 76100 Durian Tunggal, Melaka, Malaysia.

SN Applied Sciences (2019) 1:419 | https://doi.org/10.1007/s42452-019-0425-4

Received: 26 February 2019 / Accepted: 27 March 2019 / Published online: 5 April 2019 
environmental impacts of TCP and the inefficiency of conventional treatment methods for the complete removal of it from the aquatic solution, applying of advanced, quick and effective techniques, is essential.

Several methods have been investigated for the removal of chlorinated phenols, such as chemical, physical and biological treatment by using dead fungus, catalytic wet oxidation, advanced oxidation process (AOP), photocatalytic process, ion-exchange and adsorption techniques performed by Bandstra et al. [5] and Hameed et al. [15]. Most of these methods were expensive and inefficient. Thus, the adsorption of TCP from aqueous solution onto different types of an adsorbent considered as a superior method. Previously, the adsorption of TCP was limited to it is isotherm and kinetic aspect [19].

Zeolite was microporous, aluminosilicate minerals commonly used as adsorbents for several pollutants [20]. Zeolites, in general, were characterized by high specific surface areas and high cation exchange capacities (CECs). Their rigid three-dimensional structures make it free of the shrink/swell behavior. For these reasons, zeolites can offer superior sorption, hydraulic properties and have found use as molecular sieves and sorbents in wastewater treatment [32].

Activated carbon, due to its structure and high surface area, has been proposed as an adsorbent, and a suitable option for the effective removal of organic contaminations. But using of it in large scales (in engineering processes) has been limited because of problems such as filtration, dispersion, create turbidity and high cost of its reduction $[3,19]$. Some developments methods in the forming of carbonaceous layer on mesoporous material taken place in order to overcome the above problems. Carbon coated mesoporous materials may be prepared by inundate the coating of mesoporous structure into a carbon source solution, e.g. furfural alcohol and polymer $[13,24]$. In addition to the filling, carbon coating was also a very important process not only to enhance the functionality but also to give new functions to porous inorganic materials, as recently reviewed by De la Torre et al. [8]. Therefore, the resulting carbon-coated materials could be applied for the electro-chemical fields such as a porous electrode for super capacitor, fuel cell and biosensor [16].

To illustrate, if the whole surface including the pore walls, zeolite (ZSM-5) was completely and uniformly coated with carbon layer like a single graphene sheet, the coating could endow the mesoporous materials with both good chemical stability and electrical conductivity $[25,31]$ with keeping their original excellent features such as uniform mesopores, size-controllable pores and high surface area. When once zeolite surface was saliyated with silanol groups, the surface become very active toward the pyrolytic carbon deposition at as low a temperature as $500^{\circ} \mathrm{C}$ and thereby uniform carbon deposition could be easily achieved [33] by a simple carbon coated process using carbon precursor.

To the best of our knowledge, utilization of D-glucose as carbon coating precursor on mesoporous materials does not have been investigated so far. The objectives of the present study was to synthesize and characterize a Nano zero valent iron supported on zeolite (NZVI/ZSM) and Nano zero valent iron supported on carbon-coated zeolite (NZVI/SuZSM) adsorbents, assess its efficiency for TCP removal and studding the isotherm, kinetic and thermodynamic aspect of the prepared adsorbents.

\section{Methodology}

\subsection{Materials}

Sodium borohydride $\left(\mathrm{NaBH}_{4}\right) 98.5 \%$, iron (III) chloride hex hydrate $\left(\mathrm{FeCl}_{3} \cdot 6 \mathrm{H}_{2} \mathrm{O}\right) 99 \%$ were obtained from Merck. 2, 4, 6-Trichlorophenol was supplied by the Aldrich Co. with a purity of $99.8 \%$. ZSM-5 ( $\mathrm{Si} / \mathrm{Al}=30$ ) was supplied by Zeolyst International. D-glucose with purity $99 \%$ is purchased from Merck. The 2-propanol (chromatography grade), and $\mathrm{KBr}$ (IR spectroscopy grade) were purchased from Merck Millipore. Sodium hydroxide $(\mathrm{NaOH})$ and hydrochloric acid $(\mathrm{HCl})$ were obtained from Sigma-Aldrich, while analytical grade absolute ethanol and acetone were obtained from Merck and used directly without purification. Nitrogen for carbon coating step was also supplied by MOX-Linde. Sodium hydroxide $(\mathrm{NaOH})$ and hydrochloric acid $(\mathrm{HCl})$ were obtained from Sigma-Aldrich.

\subsection{Preparation and characterization}

Modification of ZSM-5 (Zeolyst International) was conducted by impregnation of $4 \mathrm{~g} Z \mathrm{ZSM}-5$ with $100 \mathrm{~mL}$ from D-glucose solution $(4 \mathrm{~g} / \mathrm{L})$ under stirring for $3 \mathrm{~h}$ at room temperature $\left(27^{\circ} \mathrm{C} \pm 2\right)$. The mixture was centrifuged and decanted to collect the solid and dried in an oven at $110^{\circ} \mathrm{C}$ for $12 \mathrm{~h}$. The solid was then carbonized in a furnace at a coveted temperature $\left(500^{\circ} \mathrm{C}\right)$ for $2 \mathrm{~h}$ in inert condition obtained by flowing $\mathrm{N}_{2}$ gas. Preparation of NZVI/ZSM and $\mathrm{NZVI/SuZSM}$ was carried out by introducing one gram and of modified carbon coated zeolite into $\mathrm{Fe}^{3+}$ solution, prepared by dissolving $0.4 \mathrm{~g} \mathrm{FeCl}_{3} \cdot 6 \mathrm{H}_{2} \mathrm{O}$ (from Merck) in $25 \mathrm{~mL}$ distilled water. Amount of one gram $\mathrm{NaBH}_{4}$ (Merck) dissolved in $50 \mathrm{~mL}$ distilled water adding drop wisely ( $3 \mathrm{~mL} /$ $\mathrm{min})$. The samples were filtered, washed via acetone and dried in an oven at $60^{\circ} \mathrm{C}$ for $60 \mathrm{~min}$. The prepared adsorbents were characterized using the $\mathrm{N}_{2}$ physisorption to evaluate the surface area and the porosity at $105^{\circ} \mathrm{C}$ prior to the analysis and the adsorption of $\mathrm{N}_{2}$ was measured at 
$-196^{\circ} \mathrm{C}$ by Micrometrics ASAP 2020. The thermal gravimetric analysis (TGA) was carried out by Mettler Toledo TGA/DSC equipped with STAR1 software in order to adjust the weight loss as temperature increases. Nitrogen of flow rate of $50 \mathrm{~mL} / \mathrm{min}$ was used as cell gas, the X-ray analysis (XRD) was conducted via Rigaku instrument, FTIR analysis was carried out by using Perkin Elmer Spectrometer 100, FESEM equipped with EDX (JEOL) and TEM (Tecnai G2 F20).

Modification of ZSM-5 (Zeolyst International) was conducted by impregnation of $4 \mathrm{~g} Z \mathrm{ZSM}-5$ with $100 \mathrm{~mL}$ from D-glucose solution $(4 \mathrm{~g} / \mathrm{L})$ under stirring for $3 \mathrm{~h}$ at room temperature $\left(27^{\circ} \mathrm{C} \pm 2\right)$. The mixture was centrifuged and decanted to collect the solid and dried in oven at $110^{\circ} \mathrm{C}$ for $12 \mathrm{~h}$. The solid was then carbonized in furnace at coveted temperature $\left(500^{\circ} \mathrm{C}\right)$ for $2 \mathrm{~h}$ in inert condition obtained by flowing $\mathrm{N}_{2}$ gas. Preparation of NZVI/ZSM and NZVI/ SuZSM was carried out by introducing one gram and of modified carbon coated zeolite into $\mathrm{Fe}^{3+}$ solution, prepared by dissolving $0.4 \mathrm{~g} \mathrm{FeCl}_{3} \cdot 6 \mathrm{H}_{2} \mathrm{O}$ (from Merck) in $25 \mathrm{~mL}$ distilled water. Amount of one gram $\mathrm{NaBH}_{4}$ (Merck) dissolved in $50 \mathrm{~mL}$ distilled water adding drop wisely ( $3 \mathrm{~mL} /$ $\mathrm{min})$. The samples were filtered, washed via acetone and dried in oven at $60^{\circ} \mathrm{C}$ for $60 \mathrm{~min}$. The prepared adsorbents were characterized using the $\mathrm{N}_{2}$ physisorption to evaluate the surface area and the porosity at $105^{\circ} \mathrm{C}$ prior to the analysis and the adsorption of $\mathrm{N}_{2}$ was measured at $-196{ }^{\circ} \mathrm{C}$ by Micrometrics ASAP 2020. The thermal gravimetric analysis (TGA) was carried out by Mettler Toledo TGA/DSC equipped with STAR1 software in order to adjust the weight loss as temperature increases. Nitrogen of flow rate of $50 \mathrm{~mL} / \mathrm{min}$ was used as cell gas, the X-ray analysis (XRD) was conducted via Rigaku instrument, FTIR analysis was carried out by using Perkin Elmer Spectrometer 100, FESEM equipped with EDX (JEOL) and TEM (Tecnai G2 F20).

\subsection{Adsorption study}

The adsorptions of the 2-, 4-, 6-Trichlorophenol (TCP) onto the adsorbents are conducted in a batch experiment. The amount of adsorbent was added into the TCP solution (of certain concentration) in the $250 \mathrm{~mL}$ conical flasks. The flasks are placed on the orbital shaker operating at $150 \mathrm{rpm}$ in room temperature $\left(27 \pm 2^{\circ} \mathrm{C}\right)$. The initial and final concentrations of TCP was determined by using UV spectrometer (Genesys 10S UV-VIS spectrophotometer) at $\lambda_{\max }=310$.

\subsection{Isotherm study}

The analysis of the pollutant adsorption process could be evaluated by the isotherm studies. The distribution of the molecules between the liquid and the solid phase could be conducted by isotherm studies at the equilibrium rate.
However, for the investigation of the sorption isotherm, Langmuir and Freundlich isotherm models are widely used [33].

Monolayer adsorption can be described by the Langmuir isotherm model. The initial of the maximum adsorption capacities corresponds to a saturated homogeneous adsorbent surface with equal energy sites that are equally available for the adsorption and monolayer of solute molecules. The energy of the adsorption process was constant and there is no transmigration of TCP in the plane of the surface [22] Langmuir isotherm model can express as Eq. 1:

$q_{e}=q_{m} b c_{e}+b c_{e}$

where $q_{e}$ is the adsorbate on the adsorbent $(\mathrm{mg} / \mathrm{g}), q_{m}$ is the maximum adsorption capacity of monolayer coverage $(\mathrm{mg} / \mathrm{g}), \mathrm{b}$ is the constant related to the binding site $(\mathrm{L} / \mathrm{mg})$, and $c_{e}$ is the concentration of molecule in the solution at equilibrium ( $\mathrm{mg} / \mathrm{L}$ ).Multilayer sorption can be described by the Freundlich model. It is used to analyse the adsorbent capacity in wastewater treatment. The adsorption on a heterogeneous surface is well described by the Freundlich model. In this model, the amount of solute adsorbed onto a given mass of sorbent is not constant at different concentrations [2].The non-linear and linear Freundlich models are expressed in Eqs. 2 and 3, respectively:

$q_{e}=k c_{e} \frac{1}{n} \quad$ (Non-linear form)

$\log q_{e}=\log k+\frac{1}{n} \log c_{e} \quad$ (Linear form)

where $k$, constant value consider as adsorption capacity indicator of the adsorbent $(\mathrm{mg} / \mathrm{g})$ in adsorption process. $\frac{1}{n}$ constant for the intensity of the adsorption. The $q_{e}$ was the adsorbate on the adsorbent $(\mathrm{mg} / \mathrm{g})$, and $c_{e}$ is the concentration at equilibrium (mg/L). Both $\mathrm{n}$ and $\mathrm{K}$ and are constants, used to indicate the linearity and the nonlinearity between the adsorbate solution concentrations and the uptake values in the adsorption process. The $n<1$ indicates poor adsorption. For $2<\mathrm{n}<10$, it indicates good adsorption as reported by Gurses et al. [12].

\subsection{Kinetic study}

The effect of time on the adsorption capacity can be evaluated by kinetic studies. A number of models was tested to identify the mechanism of the adsorption process such pseudo-first-order kinetic model and pseudo-second-order kinetic model. The first order model equation was the common adsorption model for the sorption of the solid/liquid phase [27] the Eq. 4, could be applied as follows:

$\operatorname{Ln}\left(q_{e}-q_{t}\right)=\operatorname{Ln} q_{e}-k_{1} t$ 
where $\mathrm{t}$, is the time, $q_{e}$ is the adsorbate amount at equilibrium time $(\mathrm{mg} / \mathrm{g}), q_{t}$ is the adsorbate amount at time $t$ $(\mathrm{mg} / \mathrm{g}), k_{1}$ is the rate constant of pseudo first order model $(1 / \mathrm{min})$.The kinetic for pseudo-second-order model can be described as Eq. 5:

$\mathrm{dq} / \mathrm{dt}=k_{2}\left(q_{e}-q_{t}\right)^{2}$

where $k_{2}$ is the rate constant of the pseudo second order model, ( $\mathrm{g} \mathrm{mg}^{-1} \mathrm{~min}^{-1}$ ) which can be calculated from the slop of plot $t / q_{t}$ versus $t, q_{e}$ was the adsorbate amount at equilibrium time $(\mathrm{mg} / \mathrm{g}), \mathrm{q}_{\mathrm{t}}$ is the TCP amount at time $\mathrm{t}(\mathrm{mg} / \mathrm{g})$.

\subsection{Thermodynamic study}

In environmental engineering practice, both energy and entropy factors must be considered in order to determine which process will occur spontaneously [34]. The thermodynamic parameters are calculated for this system by using Eq. 6 [30]:

$\ln k_{d}=\frac{\Delta S^{\circ}}{R}-\frac{\Delta H^{\circ}}{R T}$

where $k_{d}=$ distribution coefficient $(\mathrm{L} / \mathrm{g}), \Delta H^{\circ}=$ enthalpy $(\mathrm{kJ} / \mathrm{mol}), \Delta S^{\circ}=$ entropy $(\mathrm{J} / \mathrm{mol} \mathrm{K}), \mathrm{T}=$ temperature $(\mathrm{K})$ and $\mathrm{R}=$ gas constant $(8.314 \mathrm{~J} /$ mole $\mathrm{K})$.

\section{Result and discussion}

\subsection{Characterization}

\subsubsection{TGA analysis}

Figure 1 a shows the weight loss of ZSM within $90-110^{\circ} \mathrm{C}$. It occurs due to the loss of the hydrate surface water and the condensations of the alumina groups $(\mathrm{Al}-\mathrm{OH})$ and the
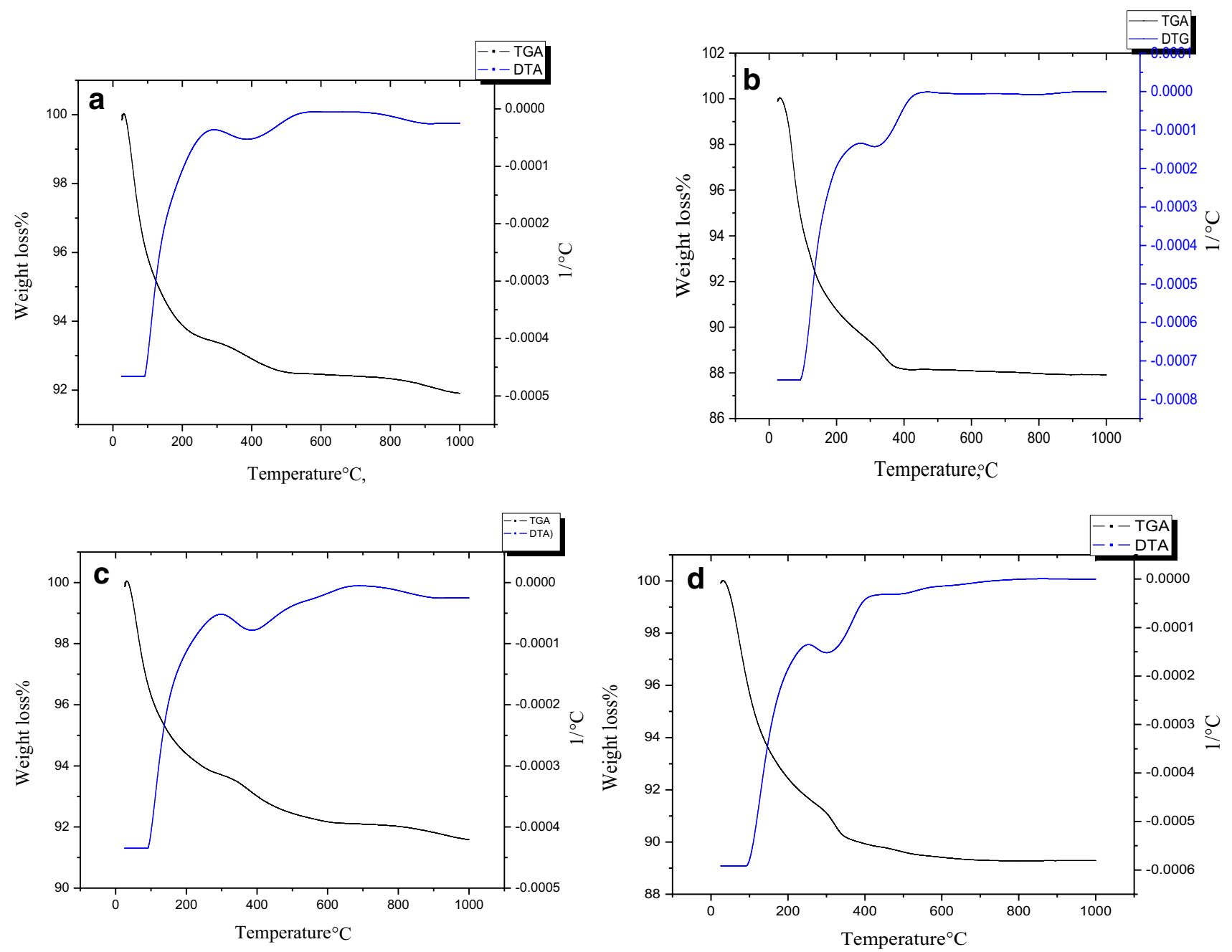

Fig. 1 TGA and DTA for a ZSM, b NZVI/ZSM, c SuZSM and d NZVI/SuZSM 
silanol groups $(\mathrm{Si}-\mathrm{OH})$ to $\mathrm{Al}-\mathrm{O}-\mathrm{Al}$ and $\mathrm{Si}-\mathrm{O}-\mathrm{Si}$, respectively. The weight loss occurred within $365-600{ }^{\circ} \mathrm{C}$ was due to the decomposition of the ZSM. Figure $1 \mathrm{~b}$ shows the weight loss of $\mathrm{NZVI} / \mathrm{ZSM}$ within $100-240{ }^{\circ} \mathrm{C}$. It occurs due to the loss of hydrate surface water and residual ethanol. Also, $\mathrm{Fe}-\mathrm{OH}$ was transformed into $\mathrm{FeO}$ or $\mathrm{Fe}^{0}$. Within $300-500{ }^{\circ} \mathrm{C}$, the weight loss is due to the decomposition of the Fe-O-Al and Fe-O-Si bonds of the adsorbent NZVI/ ZSM. Above $500^{\circ} \mathrm{C}$, no significant weight loss is observed. From Fig. 1c, the weight loss pattern of SuZSM is somewhat different from that of ZSM due to the grafting with D-glucose. Within $90-320^{\circ} \mathrm{C}$, weight lose occurs due to the loose of residual water and ethanol. At temperature ranging from 530 to $600{ }^{\circ} \mathrm{C}$, decomposition of the adsorbent SuZSM occurs. Above $600^{\circ} \mathrm{C}$, no significant weight loss is observed. Figure $1 \mathrm{~d}$ shows the weight loss of NZVI/SuZSM within $100-240^{\circ} \mathrm{C}$ which is mainly due to the loss of residual water. Within $390-480^{\circ} \mathrm{C}$, decomposition of adsorbent occurs. Above $500^{\circ} \mathrm{C}$, no significant weight loss appears. The results above show that the stability enhancement of SuZSM was more pronounced than that of ZSM when carbonization via D-glucose is performed.

\subsubsection{XRD analysis}

The XRD diffractions of NZVI/ZSM and NZVI/SuZSM are illustrated in Fig. 2. The presence of Zero Valent Iron is indicated by a distinct peak at $2 \theta$ of $44.45^{\circ}$ with detection $\left(\begin{array}{lll}1 & 1 & 1\end{array}\right)$, which is related to $a-\mathrm{Fe}(\mathrm{NZVI})$ as observed in the diffractogram of NZVI/ZSM. It appears that the ZeroValent Iron is successfully loaded into the substrate. As illustrated in Fig. 4 , the peaks are observed at $2 \theta$ of $8.22^{\circ}$, $9.09^{\circ}, 23.36^{\circ}, 24.15^{\circ}, 24.61^{\circ}$ and $30.12^{\circ}$ which are related to the crystalline structure of ZSM-5 [6]. The presence of carbon-coated surface on NZVI/SuZSM is indicated by the graphite phase at $2 \theta$ of $26.92^{\circ}, 31.56^{\circ}$. On the other hand, the peak observed at $2 \theta$ of $34.50^{\circ}$ is related to the ZSMgraphite. The apparent peak at $2 \theta$ of $45.47^{\circ}$ is related to the
ZSM-graphite- $a$-Fe. These results indicate NZVI is grafted with the carbon layer.

\subsection{3 $\mathrm{N}_{2}$-physisorption analysis}

Parameters such as surface area $\left(\mathrm{S}_{\mathrm{BET}}\right)$, pore volume and pore size of adsorbents were summarized in Table 1. The surface areas of NZVI was found to be $40.65 \mathrm{~m}^{2} / \mathrm{g}$. Meanwhile, their pore sizes was $152.70 \AA$. It was clear that the surface area and the pore size of NZVI obtained by this study was larger than that reported by Ling et al. [23], which may be attributed to different experimental conditions. In addition the surface area of the ZSM-5, carbon coated ZSM-5 (SUZSM) and the prepared adsorbents presented in Table 1.

\subsubsection{FTIR analysis}

The FTIR spectra of NZVI/ZSM and NZVI/SuZSM are shown in Fig. 3. The broad spectrum of adsorption bands at wavenumbers of $3800 \mathrm{~cm}^{-1}$ and $3400 \mathrm{~cm}^{-1}$ were related to the intermolecular $\mathrm{OH}(\mathrm{Si}-\mathrm{OH}-\mathrm{Si}$ and $\mathrm{Al}-\mathrm{OH}-\mathrm{Al})$. Also, they are related to $\mathrm{H}-\mathrm{O}-\mathrm{H}$ stretching [7]. The band at wave numbers of $1648 \mathrm{~cm}^{-1}$ and $1661 \mathrm{~cm}^{-1}$ can be attributed to $\mathrm{O}-\mathrm{H}$ bending [20]. A combination band of $\mathrm{OCH}$ and $\mathrm{COH}$ deformations from sugar molecules is indicated by a peak at the wave number of $1408 \mathrm{~cm}^{-1}$ in the $\mathrm{NZVI/SuZSM}$ spectrum.

Table 1 The surface area $\left(S_{B E T}\right)$, pore volume and pore size of the prepared adsorbents

\begin{tabular}{lclc}
\hline Adsorbent & BET $\left(\mathrm{m}^{2} / \mathrm{g}\right)$ & $\begin{array}{l}\text { BJH adsorption } \\
\text { pore volume } \\
\left(\mathrm{cm}^{3} / \mathrm{g}\right)\end{array}$ & $\begin{array}{l}\text { BJH adsorption } \\
\text { pore size (Å) }\end{array}$ \\
\hline $\mathrm{NZVI}$ & 40.65 & 0.165 & 152.70 \\
$\mathrm{ZSM}$ & 254.33 & 0.095 & 63.28 \\
$\mathrm{SuZSM}$ & 246.48 & 0.099 & 75.96 \\
$\mathrm{NZVI} /$ ZSM & 116.52 & 0.055 & 91.22 \\
$\mathrm{NZVI} / \mathrm{SuZSM}$ & 182.65 & 0.112 & 85.40 \\
\hline
\end{tabular}

Fig. 2 The XRD diffracton patterns of $\mathrm{NZVI/ZSM}$ and NZVI/ SuZSM

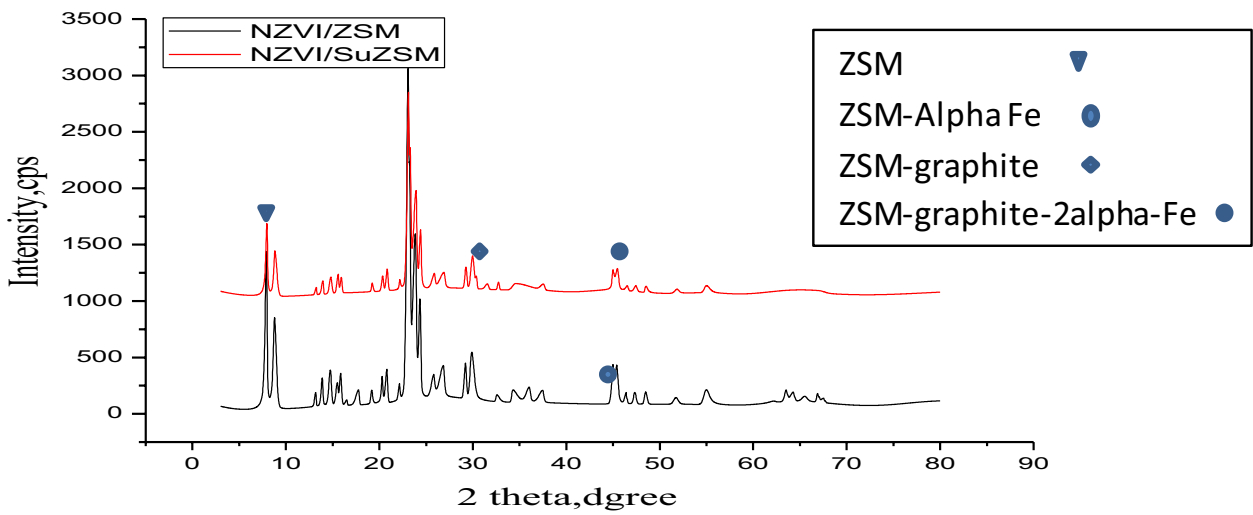

SN Applied Sciences A SPRINGER NATURE journa 
Fig. 3 The FTIR spectra of $\mathrm{NZVI} / \mathrm{ZSM}$ and $\mathrm{NZVI/SuZSM}$

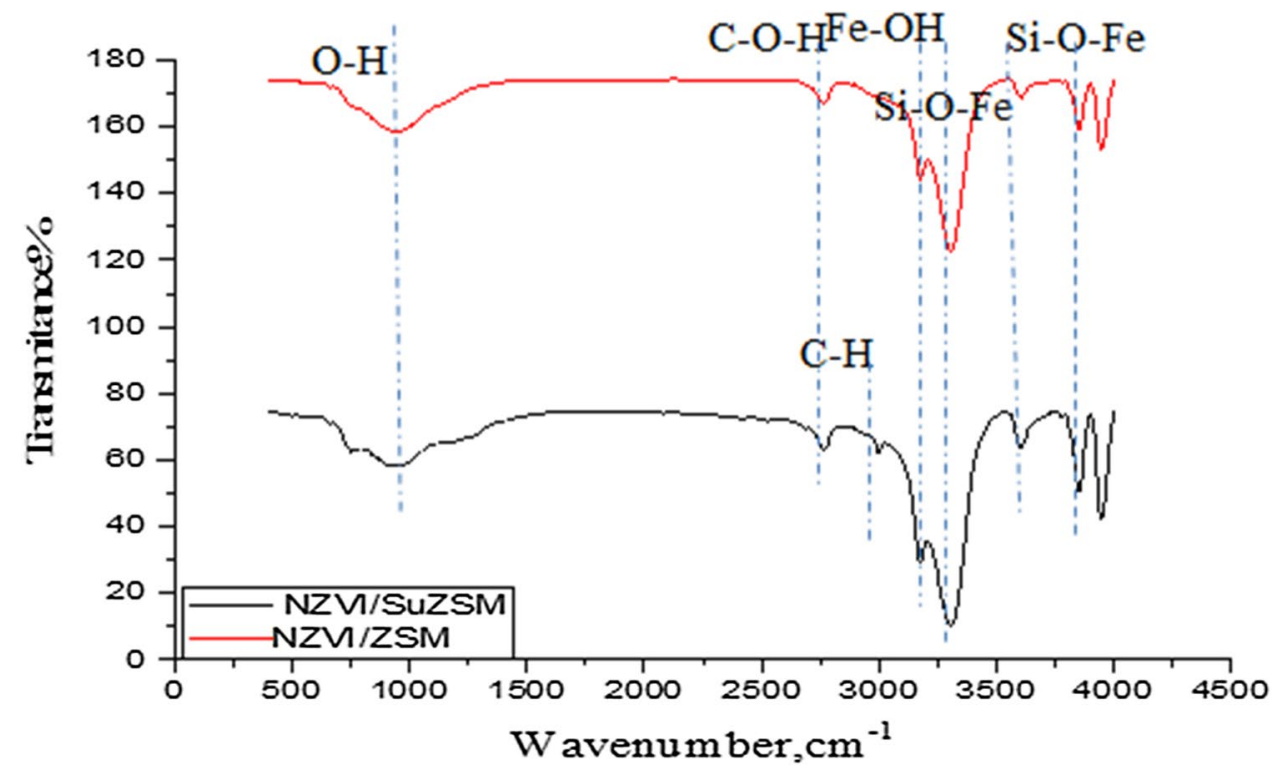

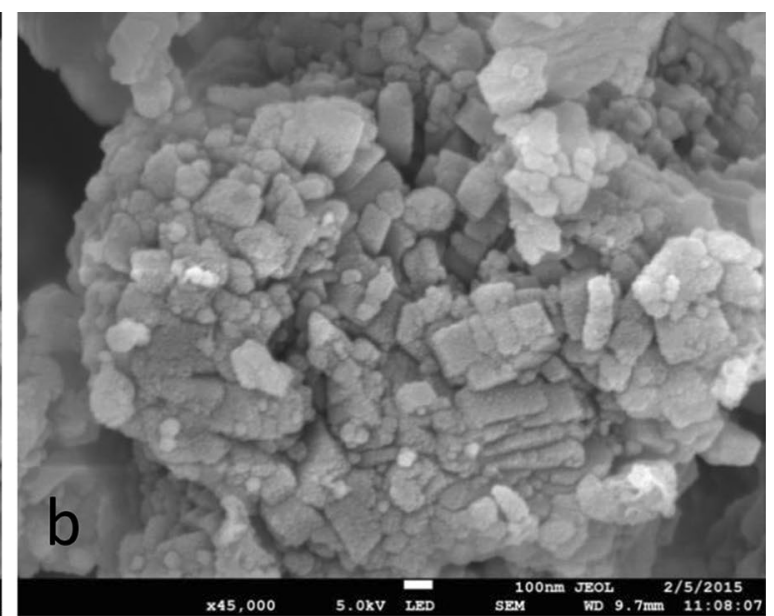

Fig. 4 The FESEM micrograph of a NZVI/ZSM at $\times 30,000$ magnification and $\mathbf{b}$ NZVI/SuZSM at $\times 45,000$ magnification

The absorption band at the wave number of $1237 \mathrm{~cm}^{-1}$ in both spectra corresponds to the $\mathrm{C}-\mathrm{H}$ in-plane bending vibrations [29]. Adsorption bands in both spectra at the wave number of $1114 \mathrm{~cm}^{-1}$ are caused by the primary oxygen single bond $(-\mathrm{C}-\mathrm{O}-\mathrm{H})[17]$, while the bands at wave numbers of $814 \mathrm{~cm}^{-1}$ and $819 \mathrm{~cm}^{-1}$ were attributed to the formation of SiO-Fe bonds [28]. Moreover, the crystalline structure of ZSM- 5 was indicated by vibration peak at around $560 \mathrm{~cm}^{-1}$ as observed by Abrishamkar and Izadi [1].

\subsubsection{FESEM analysis}

The FESEM micrographs of the prepared adsorbents are presented in Fig. 4a, b, showing the morphologies of $\mathrm{NZVI/ZSM}$ and NZVI/SuZSM, respectively. It could be $b$ seen that the modification of ZSM-5 by using impregnation of carbon affects the morphology of the substrate due to the change of the particle shape. As seen from Fig. 4a, the surface morphology of NZVI/ZSM was irregular. On the other hand, the surface morphology of NZVI/SuZSM exhibits more regular cubic shapes as shown in Fig. 4b. Furthermore, Fig. 4a, b shows that the iron nanoparticles were dispersed evenly on the surface and the pore of the substrate. This result agrees with the previous observation whereby the surface area of adsorbent was reduced after impregnation with NZVI. However, the surface area of NZVI on the surface of SuZSM was higher than that on the surface of ZSM.

On the other hand, Table 2 shows the weights and the atomic weights for the elements in ZSM-5 surface, i.e. silicon, and oxygen. The atomic/weight values of $\mathrm{Si}, \mathrm{O}$, 
Table 2 The EDX analysis of ZSM, SuZSM, NZVI/ZSM and NZVI/ SuZSM

\begin{tabular}{llrr}
\hline Adsorbents & Element (\%) & Weight (\%) & $\begin{array}{c}\text { Atomic } \\
\text { weight (\%) }\end{array}$ \\
\hline ZSM-5 & O & 60.86 & 73.15 \\
& $\mathrm{Si}$ & 37.21 & 25.47 \\
SuZSM & $\mathrm{Al}$ & 1.93 & 1.38 \\
& $\mathrm{C}$ & 14.89 & 21.12 \\
& $\mathrm{O}$ & 59.31 & 63.18 \\
& $\mathrm{Al}$ & 1.37 & 0.86 \\
NZVI/ZSM & $\mathrm{Si}$ & 24.44 & 14.83 \\
& $\mathrm{O}$ & 75.63 & 85.69 \\
& $\mathrm{Si}$ & 18.55 & 11.97 \\
& $\mathrm{Al}$ & 1.29 & 0.87 \\
& $\mathrm{Fe}$ & 4.53 & 1.47 \\
NZVI/SuZSM & $\mathrm{O}$ & 60.59 & 69.95 \\
& $\mathrm{Si}$ & 24.60 & 16.18 \\
& $\mathrm{Al}$ & 1.62 & 1.11 \\
& $\mathrm{Fe}$ & 6.23 & 2.06 \\
& $\mathrm{C}$ & 6.96 & 10.71 \\
\hline
\end{tabular}

and $\mathrm{Al}$ were found to be $25.47 \% / 37.20 \%, 73.15 \% / 60.86 \%$ and $1.37 \% / 1.93 \%$, respectively.

\subsubsection{TEM examination}

The morphology and the surface distribution of the novel adsorbent were presented in Fig. 5. The cubic structure of ZSM- 5 could be seen from the TEM micrograph (black spots) as shown in Fig. 5a. As shown in Fig. 5b, the center black spot was NZVI and the dark layer was carbon coating. Seemingly, the NZVI was surrounded by the carbon layer. As shown in Fig. 5c, the distribution of NZVI on the surface of ZSM was quite even, thereby increasing the reactivity of the prepared adsorbent. Figure $5 \mathrm{~d}$ shows the bulk structure of the adsorbent which was related to the graphite layer. It seems that there was no obvious chain structure of NZVI on the surface. Figure 5 e shows the spherical particles of NZVI on the surface of the adsorbent. The NZVI particle was surrounded by the carbon layer. Finally, Fig. $5 f$ shows that the spherical particles are surrounded by the carbon layer.

\subsection{Adsorption parameters}

A stock solution of concentration $1000 \mathrm{mg} / \mathrm{L}$ of TCP was prepared by dissolving the required amount of adsorbate in 2-Propanol for the preparation of TCP stock solution. The effect of contact time (2-180 $\mathrm{min}$ ), temperature $\left(30-50^{\circ} \mathrm{C}\right), \mathrm{pH}(2-9)$ and initial concentration $(10-40 \mathrm{mg} / \mathrm{L})$ were studied. The adsorption properties of NZVI/ZSM and
$\mathrm{NZVI/SuZSM}$ were evaluated by sorption of TCP. A stock solution of TCP was prepared via dissolving TCP in alcohol as 2-propanol instead of distilled water. The TCP considered stable compound because the resonance of the aromatic structure in addition to the low solubility in water, Cs ofChlorophenol is $210.8 \mathrm{~mol} / \mathrm{dm}^{3}$ as suggested by Kirsanov and Shishkin [21] in addition to the higher acidic strength of chlorine atom.

\subsubsection{Contact time}

Equilibrium time of adsorption was determined by using $0.1 \mathrm{~g}$ of adsorbents (NZVI/ZSM) and (NZVI/SuZSM) in $100 \mathrm{~mL}$ of $20 \mathrm{mg} / \mathrm{L} \mathrm{TCP}$ solutions. The mixture was equilibrated by shaking thoroughly at $150 \mathrm{rpm}$ in orbital shaker. Samples are taken out at different time intervals viz. 2, 4, $8,15,30,60,90,120$ and $180 \mathrm{~min}$ at $\mathrm{pH}$ value of 7 , in room temperature $\left(27 \pm 2{ }^{\circ} \mathrm{C}\right)$. At the end of the shaking period, the solution was sampled by a syringe. The samples were then centrifuged and the supplements are kept for further analysis. The equilibrium time was an important factor to set the adsorption time for each adsorbent and was found to be $90 \mathrm{~min}$ for the both tested adsorbents.

\subsubsection{Initial concentration}

The effect of initial concentration of the TCP on the adsorption performance was carried out through a series of adsorption experiments with different initial TCP concentrations ranging from 10 to $40 \mathrm{mg} / \mathrm{L}$. The experiments were performed by using a $100 \mathrm{~mL}$ TCP solution. The adsorbent dosage is $0.1 \mathrm{~g} / \mathrm{L}$. The samples used to determine the adsorption performance were available after the batch mixture was stirred for a suitable equilibrium time (90 $\mathrm{min}$ ) for both adsorbents.

\subsubsection{Temperature}

To study the temperature effect, the experiment was operating and the thermodynamic parameters such as $\Delta \mathrm{G}^{\circ}$, $\Delta \mathrm{H}^{\circ}$, and $\Delta \mathrm{S}^{\circ}$ were then determined. The effects of temperature on the adsorption equilibrium of TCP onto NZVI/ ZSM and NZVI/SuZSM were investigated and the results were presented in Fig. 6. Adsorption of TCP increased as temperature increased, indicating the endothermic adsorption process. It was found that the uptake values of NZVI/SuZSM were $16.33 \mathrm{mg} / \mathrm{g}$ while the uptake of NZVI/ ZSM was $11.93 \mathrm{mg} / \mathrm{g}$.

\subsection{4 pH}

Different $\mathrm{pH}$ values were considered: $2,4,7$ and 9 . The $\mathrm{pH}$ of the solution was measured by the $\mathrm{pH}$ meter. The 

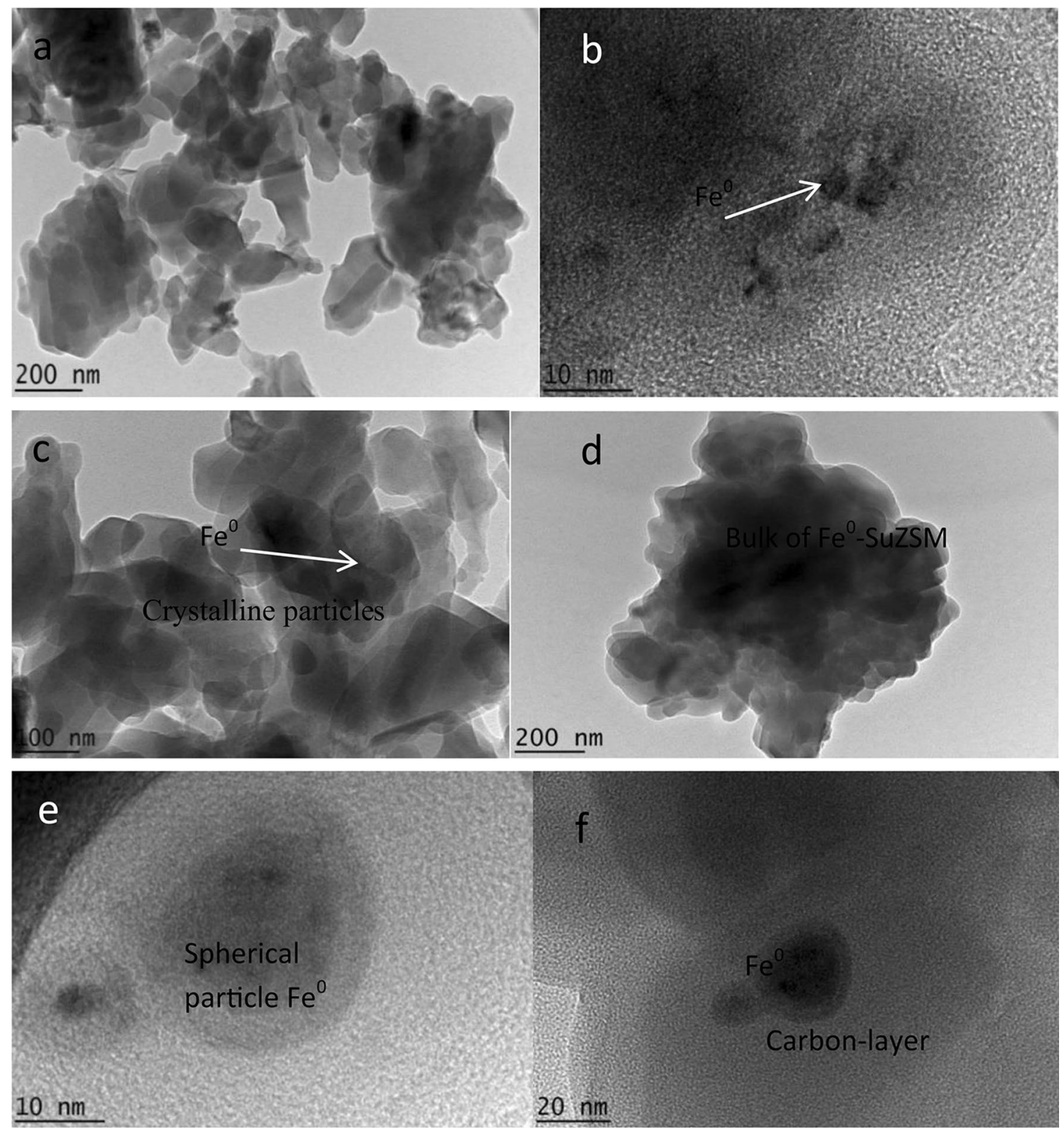

Fig. 5 The TEM examination of NZVI/SuZSM, a the crystalline particals of SuZSM surface at $200 \mathrm{~nm}$, b the black spots for NZVI surrounded with dark layer of carbon coated at $10 \mathrm{~nm}, \mathbf{c}$ the NZVI loaded on the surface of ZSM and the carbon layer at $100 \mathrm{~nm}, \mathbf{d}$ the

$\mathrm{pH}$-meter was calibrated by using a $\mathrm{pH}$ buffer of 4.0, 7.0, and 10 to ensure the accuracy of the $\mathrm{pH}$ measurement. The initial $\mathrm{pH}$ of the solution was adjusted by using $1 \mathrm{M}$ $\mathrm{HCl}$ or $1 \mathrm{M} \mathrm{NaOH}$. Then, the adsorption performance was performed. The effects of $\mathrm{pH}$ on the adsorptions of TCP onto NZVI/ZSM and NZVI/SuZSM were illustrated in Fig. 7. The unionized species of halogenated organic compounds were high, which do not favor any repulsion bulk structure of the adsorbent at $200 \mathrm{~nm}$, e the spherical particle of $\mathrm{NZVI}$ at $10 \mathrm{~nm}$ and $\mathbf{f}$ the carbon layer and the dark spots of NZVI at $20 \mathrm{~nm}$

between the adsorbent surface and the molecular species of TCP. Therefore, the electrostatic attractions between the TCP molecules and the adsorption sites increased. Besides, there was competition between the $\mathrm{OH}^{-}$ions in the adsorbent surface and the ionic species of TCP, hence reducing the TCP removal. The removal values for the adsorbents NZVI/SuZSM and NZVI/ZSM were found to be $83.40 \%$ and $62.78 \%$, respectively. 
Fig. 6 Effect of adsorption temperature on TCP adsorption onto $\mathrm{NZVI} / \mathrm{ZSM}$ and $\mathrm{NZVI} /$ SuZSM uptake
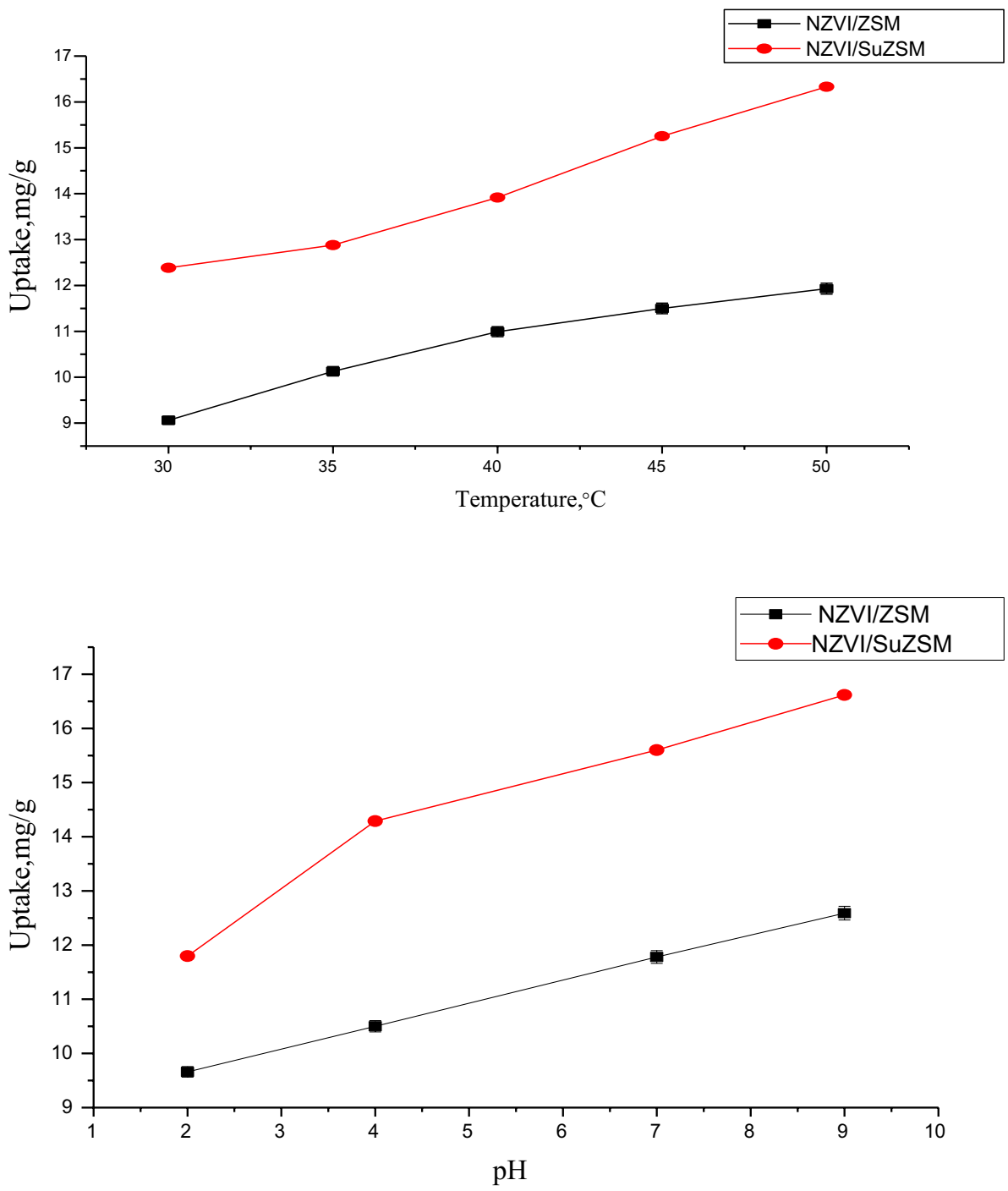

Fig. 7 Effect of initial pH of TCP solution onto $\mathrm{NZVI} / \mathrm{ZSM}$ and $\mathrm{NZVI/SuZSM}$ uptake

\subsection{Adsorption isotherm}

The isotherm studies are conducted by a series of batch adsorptions. The initial pollutant concentration is ranging from 10 to $40 \mathrm{mg} / \mathrm{L}$. The Langmuir and Freundlich isotherm models for adsorption of TCP onto NZVI/ZSM and NZVI/ SuZSM are presented in Fig. $8 \mathrm{a}$, b respectively. The vertical error bars on the data points indicated the average deviation from triplicate the data collection. The Langmuir and Freundlich constants of adsorption of TCP onto NZVI/ZSM are $0.033 \mathrm{~L} / \mathrm{mg}$ and $1.21 \mathrm{~g} / \mathrm{L}$, respectively, while the Langmuir and Freundlich constants of adsorption of TCP onto $\mathrm{NZVI} / \mathrm{SuZSM}$ are $0.05 \mathrm{~L} / \mathrm{mg}$ and $2.16 \mathrm{~g} / \mathrm{L}$, respectively. The maximum adsorption capacities of TCP onto NZVI/ZSM and $\mathrm{NZVI/SuZSM}$ are $22.27 \mathrm{mg} / \mathrm{g}$ and $30.58 \mathrm{mg} / \mathrm{g}$, respectively (from Langmuir isotherm). In general, the Freundlich isotherm characterizes the adsorption process better than the Langmuir isotherm for NZVI/ZSM, while Langmuir isotherm characterizes the adsorption process better than the Freundlich isotherm for NZVI/SuZSM. The $1 / \mathrm{n}$ value of the Freundlich isotherm is $\sim 1.0$ for both NZVI/ZSM and $\mathrm{NZVI/SuZSM}$. Hence, the adsorption of TCP onto NZVI/ ZSM can be considered as multilayer adsorption while the adsorption of TCP onto NZVI/SuZSM can be considered as monolayer adsorption. The parameters obtained by fitting the results to the Langmuir and Freundlich isotherm models are summarized in Table 3.

From the experimental data, it seems that the fitting errors of both Langmuir and Freundlich isotherm models for NZVI/ZSM and NZVI/SuZSM were smaller than one $\left(R^{2} \sim 1\right)$. However, the Langmuir isotherm model gives a smaller fitting error for the adsorbent NZVI/ZSM than the Freundlich isotherm model indicating multilayer adsorption. On the other hand, the correlation coefficients $\left(R^{2}\right)$ of Langmuir for the adsorbent NZVI/SuZSM of a high value indicating monolayer adsorption. The correlation coefficients $\left(R^{2}\right)$ indicating that the experimental data of the adsorptions for adsorbents as NZVI/ZSM and NZVI/SuZSM 

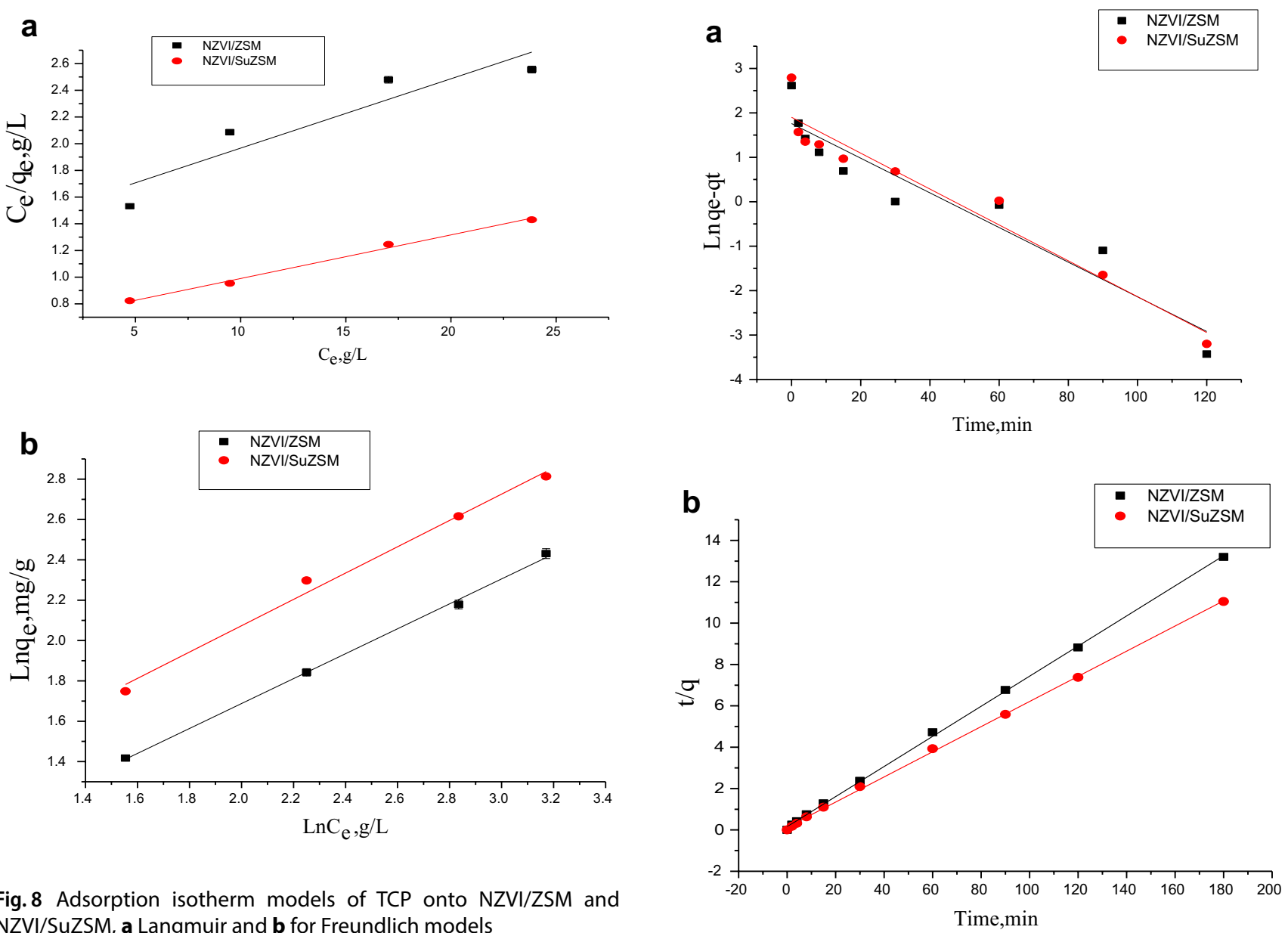

Fig. 8 Adsorption isotherm models of TCP onto NZVI/ZSM and $\mathrm{NZVI/SuZSM}$, a Langmuir and $\mathbf{b}$ for Freundlich models

are well fitted with both isotherm models. The fitting of the Langmuir and Freundlich isotherm models are summarized in Table 3. Also, the maximum uptake values of all the adsorbents are comparable with other adsorbents reported in Table 3 in monolayer adsorption.

\subsection{Kinetic studies}

The kinetic studies are conducted by a series of batch adsorptions running at initial pollutant concentration of $20 \mathrm{mg} / \mathrm{L}$. The procedures of kinetic adsorption tests are

Fig. 9 Linear plot of a pseudo-first kinetic model and $\mathbf{b}$ pseudosecond kinetic model of adsorption of TCP onto NZVI/ZSM and $\mathrm{NZVI/SuZSM}$ uptake

identical to those of batch equilibration tests. However, the aqueous samples are taken at various time intervals. The result of the kinetic study of TCP adsorption on $\mathrm{NZVI/ZSM}$ and NZVI/SuZSM was presented in Fig. 9a, b. It seems that the second order model fits well with the experimental data with a higher R2 value. Thus, it shows that the pseudo-second-order model is more suitable

Table 3 Isotherm parameters of the adsorption of TCP onto NZVI/ZSM and NZVI/SuZSM comparison with literature studies in uptake values

\begin{tabular}{|c|c|c|c|c|c|c|c|}
\hline \multirow[t]{2}{*}{ Absorbents } & \multicolumn{3}{|l|}{ Langmuir } & \multicolumn{3}{|c|}{ Freundlich } & \multirow[t]{2}{*}{ References } \\
\hline & $\mathrm{K}_{\mathrm{L}}(\mathrm{L} / \mathrm{mg})$ & $\mathrm{q}_{\max }(\mathrm{mg} / \mathrm{g})$ & $\mathrm{R}^{2}$ & $K_{f}(g / L)$ & $1 / \mathrm{N}$ & $\mathrm{R}^{2}$ & \\
\hline NZVI/ZSM & 0.033 & 22.27 & 0.9083 & 1.21 & 0.65 & 0.9933 & This study \\
\hline NZVI/SuZSM & 0.05 & 30.58 & 0.9946 & 2.16 & 0.65 & 0.9915 & This study \\
\hline Activated carbon/loosestrife & 0.15 & 367.64 & 0.5222 & 24.06 & 0.79 & 0.9009 & Fan et al. [9] \\
\hline surfactant-modified zeolitic tuff & 0.023 & 12.90 & 0.9901 & & & & Naddfi et al. [26] \\
\hline Activated carbon SKD515 & 0.40 & 12.20 & 0.7800 & 4.98 & 0.32 & 0.9213 & Shishkin and Kirsanov [21] \\
\hline Activated clay & 0.022 & 123.46 & 0.9300 & 4.42 & 0.69 & 0.9600 & Hameed et al. [14] \\
\hline
\end{tabular}


Table 4 Kinetic parameters of the adsorption of TCP onto, $\mathrm{NZVI} / \mathrm{ZSM}$ and $\mathrm{NZVI/SuZSM}$ were collected in this study

Fig. 10 Van't Hoff plot of effect of temperature on adsorption properties of TCP onto NZVI/ ZSM and NZVI/SuZSM

\begin{tabular}{llllllll}
\hline Adsorbents & $\mathrm{K}_{1}\left(\mathrm{~min}^{-1}\right)$ & $\mathrm{q}_{\mathrm{e}, \text { cal }}(\mathrm{mg} / \mathrm{g})$ & $\mathrm{R}^{2}$ & $\mathrm{k}_{2}(\mathrm{~g} / \mathrm{mg} \min )$ & $\mathrm{q}_{\mathrm{e}, \text { cal }}(\mathrm{mg} / \mathrm{g})$ & $\mathrm{R}^{2}$ & $\mathrm{q}_{\mathrm{e}}(\mathrm{mg} / \mathrm{g})$ \\
\hline $\mathrm{NZVI} / Z S M$ & 0.039 & 5.81 & 0.9064 & 0.034 & 13.73 & 0.9995 & 13.63 \\
$\mathrm{NZVI} / \mathrm{SuZSM}$ & 0.040 & 6.69 & 0.9408 & 0.029 & 16.29 & 0.9994 & 16.29 \\
\hline
\end{tabular}

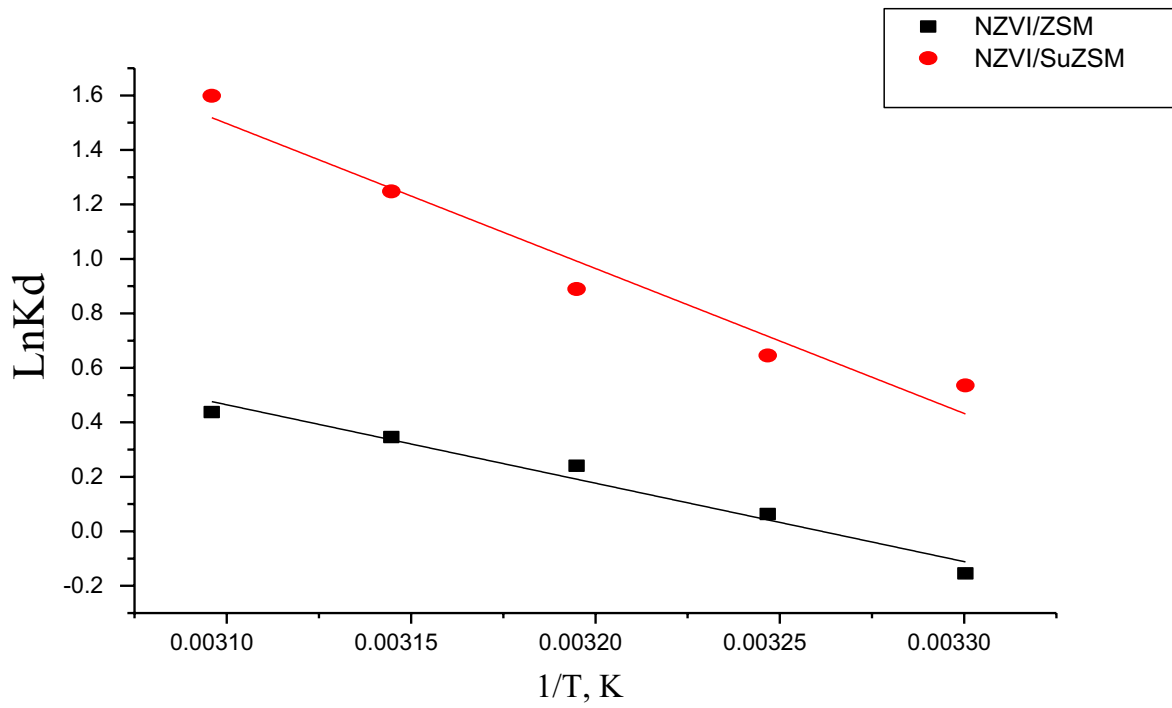

to be applied in the kinetic studies for NZVI/ZSM, and $\mathrm{NZVI/SuZSM}$. The kinetic parameters for the adsorbents such as $\mathrm{NZVI/ZSM}$, and NZVI/SuZSM were summarized in Table 4.

Thus, the experimental data indicates that the pseudo-second-order model is more suitable to be applied in the kinetic studies for NZVI/ZSM, and NZVI/ SuZSM and the $\mathrm{q}_{\mathrm{e}^{\prime} \mathrm{Cal}}$ value near to the $\mathrm{q}_{\mathrm{e}}$ experimental. The kinetic parameters for the adsorbents NZVI/ZSM and $\mathrm{NZVI/SuZSM}$ are summarized in Table 4.

\subsection{Thermodynamic studies}

Thermodynamic study of adsorption is carried out by equilibrating the TCP solution with an adsorbent at various temperatures ranging from 30 to $50{ }^{\circ} \mathrm{C}$. The thermodynamic studies are conducted by a series of batch adsorptions running at initial pollutant concentration of $20 \mathrm{mg} / \mathrm{L}$. The objectives of this study are to evaluate the changes in enthalpy $\left(\Delta \mathrm{H}^{\circ}\right)$, entropy $\left(\Delta \mathrm{S}^{\circ}\right)$ and Gibb's free energy $\left.\Delta G^{\circ}\right)$ of adsorption [11].

The values of $\Delta \mathrm{H}^{\circ}, \Delta \mathrm{S}^{\circ}, \Delta \mathrm{G}^{\circ}$ are calculated from Fig. 10 and listed in Table 5. Positive $\Delta \mathrm{H}^{\circ}$ value indicates endothermic adsorption. This is supported by the fact that the adsorption of TCP increases as temperature increases. The positive $\Delta S^{\circ}$ reveals that the degree of freedom increases at the solid-liquid interface during adsorption. The $\Delta G^{\circ}$ is negative when adsorption happens on
$\mathrm{NZVI/SuZSM}$, reflecting the spontaneity of the process. On the other hand, the adsorption process for NZVI/ZSM is un-spontaneous and difficult to apply in practice in temperature $30^{\circ} \mathrm{C}$ and thermodynamically feasible in another temperature.

\section{Conclusion}

In this study, adsorbents such as NZVI/ZSM and NZVI/SuZSM have been successfully synthesized. The prepared adsorbents are characterized by XRD, FTIR, $\mathrm{N}_{2}$-Physisorption, TGA, TEM, and FESEM-EDX. The performances of NZVI are compared in terms of TCP adsorption with the uptake onto ZSM and SUZSM, and adsorbents such as SuZSM show good performance. For the application of D-glucose as a novel additive in the carbon-coating technique, it is found that the optimal activation temperature is $500^{\circ} \mathrm{C}$. In addition, the carbonization performed via D-glucose increases the adsorption capacity of TCP onto the activated inorganic supports such as ZSM. The modification performed with D-glucose via the wet impregnation method followed by the carbonization step can significantly improve the adsorption rate and the adsorption capacity. The spontaneity of the adsorption process is determined from the free energy $\Delta G^{\circ}$. Meanwhile, $\Delta \mathrm{H}^{\circ}$ indicates the process of whether it is endothermic or exothermic. $\Delta S^{\circ}$ signifies the randomness of the system. Carbon-coated technique leads to improving the physical property of the prepared adsorbents. In addition carbon-coated 
Table 5 Thermodynamic parameters for adsorption of TCP onto NZVI/ZSM and $\mathrm{NZVI/SuZSM}$ compared with literature review

\begin{tabular}{lcllllll}
\hline Adsorbent & $\Delta \mathrm{H}^{\circ}(\mathrm{kJ} / \mathrm{mol})$ & $\Delta \mathrm{S}^{\circ}(\mathrm{J} / \mathrm{mol} \mathrm{K})$ & \multicolumn{2}{l}{$\Delta \mathrm{G}^{\circ}(\mathrm{J} / \mathrm{mol})$} & References \\
\cline { 4 - 6 } & & & $303 \mathrm{~K}$ & $313 \mathrm{~K}$ & $323 \mathrm{~K}$ & \\
\hline $\mathrm{NZVI} /$ ZSM & 23.936 & 78.066 & 282.038 & -498.621 & -1279.28 & This study \\
$\mathrm{NZVI/SuZSM}$ & 44.239 & 149.59 & -1084.63 & -2580.48 & -4076.33 & This study \\
Montmorillonite & -28.788 & 81 & -3392 & -2580 & -1769 & Fil et al. [10] \\
MGC-4 & 87.200 & 47.22 & -20850 & -5591.73 & 6054.6 & Wang et al. [33] \\
$\begin{array}{llllll}\text { Modified malted } \\
\text { sorghum mash }\end{array}$ & 38.31 & 68.16 & & -21260 & -2200 & Oyelude and \\
Mesoporous silica & 55.13 & 235.8 & & & & Appiah-Takyi \\
[27]
\end{tabular}

adsorbents provided higher adsorption efficiency due to the synergistic effect, the available active adsorption site of the supporting materials and the stability of the NZVI. The evaluation of the adsorption performance of the prepared adsorbents was proven via the isotherm studies by Langmuir and Freundlich models. In the kinetic study, the pseudo first order and the pseudo-second-order kinetic models are examined. It seems that the pseudo-second-order kinetic model fits well with the experimental data for both adsorbents. As result the both adsorbents are spontaneity and thermodynamically feasible. This study offers solutions to overcome the industrial wastewater problems especially in the field of organic pollutant removal.

Acknowledgements The author would like to thanks the ministry of science and technology_Iraq for their Scientific supports.

\section{Compliance with ethical standards}

Conflict of interest The authors declare that they have no conflict of interest.

Ethical approval This article does not contain any studies with human participants or animals performed by any of the authors.

\section{References}

1. Abrishamkar M, Izadi A (2013) Nano-ZSM-5 zeolite: synthesis and application to electrocatalytic oxidation of ethanol. J Microporous Mesoporous Mater 180:56-60

2. Abdel Ghafar HH, Fouad OA, Ali GAM, Makhlouf SA (2013) Enhancement of adsorption efficiency of methylene blue on $\mathrm{Co}_{3} \mathrm{O}_{4} / \mathrm{SiO}_{2}$ nano composite. J Desalin Water Treat 53(11):2980-2989

3. Atkinson JD, Fortunato ME, Dastgheib SA, Rostam-Abadi M, Rood MJ, Suslick KS (2014) Synthesis and characterization of iron-impregnated porous carbon spheres prepared by ultrasonic spray pyrolysis. J Carbon 49:587-598

4. Aifiei Y, Haoran L, Yali F, Zhuwei D (2015) Mechanism of 2, 4, 6-Trichlorophenol degradation in microbial fuel cells system with microbe isolated from submarine sediment. Int J Electrochem Sci 10:1459-1468
5. Bandstra JZ, Tratnyek PG, Johnson RL, Miehr R (2005) Reduction of 2, 4, 6-Trinitrotoluene by iron metal: kinetic controls on product distributions in batch experiments. J Sci Technol 39:230-238

6. Canli M, Bayca SU, Abali Y (2013) Removal of methylene blue by natural and $\mathrm{Ca}$ and $\mathrm{K}$-exchanged zeolite treated with hydrogen peroxide. J Physicochem Probl Miner Process 49(2):481-496

7. Cho YI, Kim BH, Kim SJ, Yun JJ, Lee H, Park SH, Jung SC (2013) Preparation and characterization of zero valent iron powders via transfer type redactor using iron oxide from the acid regeneration process. Adv Powder Technol 24:858-886

8. De la Torre AIR, Dominguez JM, Sandoval G, Torres Rodriguez M, Ramos CE, Melo-Banda JA, Angeles RC (2010) Synthesis of hybrid (Ni-Mo) carbides/carbon-coated mesoporous materials and their catalytic properties for hydrocracking of intermediate paraffins (n-C8). J Catal Today 148(1-2):55-62

9. Fan J, Shi Q, Zhang J, Zhang Ch, Ren L (2011) Adsorption of 2, 4, 6-Trichlorophenol from aqueous solution onto activated carbon derived from loosestrife. J Desalin 267:139-146

10. Fil BA, Korkmaz M, Özmetin C (2012) Cationic dye (methylene blue) removal from aqueous solution by montmorillonite. J Bull Korean Chem Soc 33(10):3184-3190

11. Fungaro D, Borrelyb SI, Izidoro JC, Grosche LC, Pinheiro AS (2010) Adsorption of methylene blue from aqueous solution on zeolite material and the improvement as toxicity removal to living organisms. Orbital- Electron J Chem 2(3):235-247

12. Gurses A, Yalcin M, Bayrak R, Dogar C, Karaca S, Acikyildiz M (2006) The adsorption kinetics of the cationic dye, methylene blue, onto clay. J Hazard Mater 131:217-228

13. Gupta VK, Saleh TA, Agarwal Sh (2011) Synthesis and characterization of alumina-coated carbon nanotubes and their application for lead removal. J Hazard Mater 185(1):17-23

14. Hameed BH, Latiff KN, Ahmad L (2007) Adsorption of basic dye (methylene blue) onto activated carbon prepared from rattan sawdust. J Dyes Pigments 75(1):143-149

15. Hameed BH (2009) Removal of cationic dye from aqueous solution using jackfruit peel as non-conventional low-cost adsorbent. J Hazard Mater 162:344-350

16. Hoshikawa $Y$, Kyotani T, Komiyam H, Castro-Muniz A, Nanbu H, Yokoyam T, Ishli T (2014) Remarkable enhancement of pyrolytic carbon deposition on ordered mesoporous silicas by their trimethylsilylation. J Carbon 67:156-167

17. Hussein S, Choong Y, Khan MA, Malekbala MR, Thomas S, Cheah W (2011) Carbon coated monolith, a mesoporous material for the removal of methyl orange from aqueous phase: adsorption and desorption studies. Chem Eng J 171(3):1124-1131

18. Kareem SH, Jalhoom MG, Ali IH (2014) Synthesis and characterization of organic functionalized mesoporous silica and evaluate 
their adsorptive behavior for removal of methylene blue from aqueous solution. Am J Environ Sci 10(1):48-60

19. Krishnaiah D, Sarbatly R, Anisuzzaman SM, Bono A (2013) Adsorption of 2, 4, 6-Trichlorophenol (TCP) onto activated carbon. J King Saud Univ 25(3):251-255

20. Kim SA, Oh BT, Kannan SK, Kim HM, Lee WH, Lee KJ, Shea PJ, Park YJ (2013) Removal of $\mathrm{Pb}$ (II) from aqueous solution by a zeolitenanoscale zero-valent iron composite. Chem Eng J 217:54-60

21. Kirsanov MP, Shishkin VV (2016) Evaluation and improving the efficiency of the use of activated carbon for the extraction of organo chlorine compound in water technology. Foods Raw Mater 4(1):148-153

22. Lata H, Gupta RK, Garg VK (2007) Removal of a basic dye from aqueous solution by adsorption using Partheniumhysterophorus: an agricultural waste. J Dyes Pigments 74:653-658

23. Ling X, Li J, Zhu W, Zho Y, Shen J, Sun X, Han W, Jiangsu LW (2012) Synthesis of nanoscale zero-valent iron/ordered mesoporous carbon for adsorption and synergistic reduction of nitrobenzene. J Chemosphere 87(6):655-660

24. Malekbala MR, Hussein S, Abdullah LCh, Choong ThSY, Khan MA (2015) Adsorption/desorption of cationic dye on surfactant modified mesoporous carbon coated monolith: equilibrium, kinetic and thermodynamic studies. J Ind Eng Chem 21:369-377

25. Nishihara H, Kwon T, Fukura Y, Iwamura S, Hoshikawa $Y$, Nakayama W (2011) Fabrication of a highly conductive ordered porous electrode by carbon-coating of a continuous mesoporous silica film. J Chem Mater 23(13):3144-3151

26. Naddafi K, Nabizadeh R, Sarkhosh M, Gholami M, Saeedi R, Rastkari N (2016) Adsorption of 2, 4, 6-Tricholophenol from aqueous solutions by a surfactant-modified zeolitic tuff: batch and continuous studies. J Desalin Water Treat 57(13):5789-5799
27. Oyelude EO, Appiah-Takyi F (2012) Removal of methylene blue from aqueous solution using alkali-modified malted sorghum mash. Turk J Eng Environ Sci 36(2):161-169

28. Petala E, Karakassides MA, Dimos K, Zboril R, Douvalis A, Tucek J, Bakas T (2013) Nano scale zero-valent iron supported on mesoporous silica: characterization and reactivity for $\mathrm{Cr}(\mathrm{VI})$ removal from aqueous solution. J Hazard Mater 216(2):295-306

29. Qiu X, Xu Z, Lianga B, Fang Z, Gu F (2011) Degradation of decabromodiphenyl ether by nano zero-valent iron immobilized in mesoporous silica microspheres. J Hazard Mater 193:70-81

30. Sarioglu M, Atay U (2006) Removal of methylene blue by using biosolid. Glob NEST J 8(2):113-120

31. Tumsek F, Koyuncui Z, Bodur G, Bayindir Z (2015) Adsorption of 2,4,6-Trichlorophenol on activated carbon. J Turk Chem Soc, Sect A: Chem 2(3):22-32

32. Wang W, Wang X, Zhou M, Yue J, Mao Q (2010) Novel NaY zeolite-supported nanoscale zero-valent iron as an efficient heterogeneous Fenton catalyst. J Catal Commun 11:937-941

33. Wang P, Cao M, Qian J, Wang Ch, Ao Y, Hou J (2014) Kinetics and thermodynamics of adsorption of methylene blue by a magnetic graphene-carbon nanotube composite. J Appl Surf Sci 290:116-124

34. Wu X, Huib KN, Lee SK, Huia KS, Hwang DH, Chen R, Zhoud W, Son YG, Cho YR (2012) Adsorption of basic yellow 87 from aqueous solution onto two different mesoporous adsorbents. Chem Eng J 180:91-98

Publisher's Note Springer Nature remains neutral with regard to jurisdictional claims in published maps and institutional affiliations. 